\title{
Correlation between Academic Performance in Medical Technology Professional Subjects and Licensure Examination Results
}

\author{
Dr. Irynne D. Cabanban* \\ Associate Professor, School of Medical Technology, school of Nursing Centro Escolar University, Manila, \\ Philippines \\ *Corresponding Author: Dr. Irynne D. Cabanban, Associate Professor, School of Medical Technology, \\ school of Nursing Centro Escolar University, Manila, Philippines
}

\begin{abstract}
The main thrust of the study is to determine the correlation of academic performance in medical technology professional subjects and the licensure examination results to serve as basis for a proposed InHouse Review Enhancement Program. The study will provide an avenue in strengthening identified weak areas of the medical technology course thus provide remedial measures prior to the conduct of licensure examination. The study made used of the Descriptive Correlation type of research with the use of documentary analysis as tool for data gathering. Majority of graduates demonstrated a "satisfactory" academic performance in majority of the medical technology professional subjects but licensure examination results were "barely satisfactory". A "substantial" correlation between academic performance and board examination results were noted among graduates belonging to curriculum year 2005-2006 and 2006 -2007 but a "low correlation" for those under curriculum year 2002-2003. Chemistry and Blood banking subjects predict performances in the licensure examination. In general, academic performance in medical technology professional subjects and results of licensure examination revealed "low" to "substantial" correlation in majority of graduates who took the licensure examination from September 2006 to September 2010. Therefore, there is a need to propose an in-house review enhancement program.
\end{abstract}

Keywords: Academic Performance, Licensure Examination, Medical Technology

\section{INTRODUCTION}

Clinical laboratory testing plays a crucial role in the detection, diagnosis, and treatment of disease. Medical technologists also known as Clinical Scientists in the United States or Biomedical Scientists in some other countries perform most of these tests. They do complex chemical, biological, hematological, immunologic, microscopic, and bacteriological tests. To ensure the accuracy of tests, medical technologists evaluate test results, develop and modify procedures, and establish and monitor programs. Although they do not often interact directly with patients, the work completed by medical technologists directly impacts patients' lives. Physicians rely on the information provided by medical technologists to determine the diagnosis and treatment of their patients.

The complexity of tests performed, the level of judgment needed, and the amount of responsibility that medical technologists assume depend largely on the amount of education and experience they have. Furthermore, critical to high-quality health care is the assurance that individuals performing laboratory tests are able to carry out their responsibilities in a proficient manner. Therefore, laboratory personnel of demonstrated competence are of prime importance.

Here in the Philippines, the usual requirement for an entry-level position as a medical technologist is a four-year degree in Bachelor of Science in Medical Technology or Bachelor of Science in Public Health and Hygiene and a certification of passing the National Licensure Examination for Medical Technologists given by the Professional Regulation Commission.

The primary objective of the professional licensure examination is to obtain valid and reliable information as to whether examinees possess the technical competence required for admission to the 
profession. Technical competence includes technical knowledge, the ability to apply such knowledge skillfully and with good judgment and an understanding of professional responsibility.

For almost 52 years now, the selected university School of Medical Technology had produced an enormous number of students who passed the national licensure exam for medical technologists. In addition, most students who graduated with honors or other commendations even topped the board exam. The most recent was last March 2011 where the school placed fifth, eighth and ninth. Being the first school of Medical Technology with level IV accredited status, the school continuously directed its effort to improve the percentage of passing in the national licensure examination of their graduates.

Recognizing the value attributed to success in the licensure exam, it is therefore imperative for school administrators, dean and faculty members to continuously engage in various studies that correlate with board examination performances. It is through this context that the researcher conceptualized this study which aims to determine the relationship between academic performance in medical technology professional subjects and the licensure examination results. Knowledge derived from the findings of this study will be utilized to design an effective in-house review enhancement program that will theoretically prepare their graduates before they take the said examination. Likewise, faculty members can gain insights as to how graduates performed in each of the subtest of the licensure examination for the past five years. Thus, aid in the formulation of corrective measures that will improve both academic performance and licensure examination ratings.

This study aimed to determine the academic performance of the graduates in the medical technology professional subjects and subtests in licensure examination and to correlate the academic performance and performance in subtests of the licensure examination.

\section{MATERials AND MeTHOD}

\subsection{Research Design}

The researcher utilized the descriptive method of research in this study. In this study the correlation method will be utilized to establish the relationship between academic performance in medical technology professional subjects and licensure examination results. The degree of relationship will be measured by determining the coefficient of correlation between the given variables.

\subsection{Participants}

Table 1. Distribution of Participants

\begin{tabular}{|c|c|}
\hline Date of Examination & Population \\
\hline September 2006 & 62 \\
\hline March 2007 & 83 \\
\hline September 2007 & 104 \\
\hline March 2008 & 28 \\
\hline September 2008 & 71 \\
\hline March 2009 & 61 \\
\hline September 2009 & 29 \\
\hline March 2010 & 25 \\
\hline September 2010 & 43 \\
\hline Total & $\mathbf{5 0 6}$ \\
\hline
\end{tabular}

The sample frame of this study consisted of 506 graduates from a slected University, College of Medical Technology who took the national licensure examination from September 2006-September 2010, covering a period of five years. The researcher decided not to include those with history of failure in the licensure examination to obtain a more valid assessment on how prepared the graduates are before taking the licensure examination for the first time, thus, can also aid in evaluating the effectiveness of in-house review program. Table 1 shows the distribution of respondents in the different examination periods.

\subsection{Research Instrument}

The researcher asked the permission from Student Record and Management Department of the University to allow access on the grades of the graduates in medical technology professional subjects. The licensure examination ratings in the different subtests furnished by the Professional Regulation 
Commission to the College of Medical Technology were also needed in this study thus, permission from the dean of the college was sought.

The instructors' report of the academic performance of students was based on the ten-scale grading system used by CEU, where 1.0 is the highest and 5.0 is the lowest. The ten scale grading system and their percentile equivalent will be used to describe the academic performance of students in medical technology professional subjects. This was done to determine the relationship between academic performance and the board examination ratings in various subtests since the results of the board examination are expressed in this grading system.

Given below are the ten-scale grading system with their percentage equivalent, average of their percentage equivalent and the corresponding verbal interpretation.

Table 2. Grading System in the University

\begin{tabular}{|c|c|c|c|}
\hline Grades & Percentage Equivalent (PE) & PE Average & Verbal Interpretation \\
\hline 1.00 & $98-100$ & 99 & Excellent \\
\hline 1.25 & $95-97$ & 96 & Superior \\
\hline 1.50 & $92-94$ & 93 & Superior \\
\hline 1.75 & $89-91$ & 90 & Very Satisfactory \\
\hline 2.0 & $86-88$ & 87 & Very Satisfactory \\
\hline 2.25 & $83-85$ & 84 & Satisfactory \\
\hline 2.50 & $80-82$ & 81 & Satisfactory \\
\hline 2.75 & $77-79$ & 78 & Fairly Satisfactory \\
\hline 3.0 & $75-76$ & 75.50 & Barely Satisfactory \\
\hline 5.0 & $60-74$ & 67 & Unsatisfactory \\
\hline
\end{tabular}

\subsection{Data Analysis}

The data were analyzed using descriptive statistics such as weighted mean and standard deviation and inferential statistics such as Pearson product moment correlation and Multiple regression.

\section{RESULTS}

\subsection{Academic Performance of Graduates in Medical Technology Professional Subjects in Three Curriculum Years}

The data indicates that academic performance of graduates in medical technology professional subjects are all described as "satisfactory" in three different curriculum years.

Table 3. Graduates' Performance in Medical Technology Professional Subjects in Three Curriculum Years

\begin{tabular}{|c|c|c|c|}
\hline Subjects & CY 2002-2003 & CY 2005-2006 & CY 2006-2007 \\
\hline Clin. Chemistry & 70.81 & 75.17 & 76.53 \\
\hline Micro-Para & 75.53 & 76.85 & 82.35 \\
\hline Hematology & 69.79 & 72.04 & 78.47 \\
\hline BB-Serology & 72.86 & 76.19 & 76.53 \\
\hline Clin. Microscopy & 73.48 & 78.92 & 81.93 \\
\hline Histopath-MTLE & 73.20 & 76.59 & 80.44 \\
\hline MEAN & $\mathbf{7 2 . 6 1}$ & $\mathbf{7 5 . 9 6}$ & $\mathbf{7 9 . 3 8}$ \\
\hline Verbal Interpretation & Unsatisfactory & Barely Satisfactory & Fairly Satisfactory \\
\hline
\end{tabular}

\subsection{Board Performance of Graduates in Different Subtest of Licensure Examination in Three Curriculum Years}

Graduates under curriculum 2006-2007 performed better in all of the subtests of the licensure examination as compared to graduates belonging to curriculum year 2002-2003 and 2006- 2007 as shown by an average mean of 79.38 indicating a "fairly satisfactory" performance. In addition, performance in the licensure examination also improved during curriculum year 2005-2006 as evidenced by a passing average rate of 75.96 , much higher than those obtained by graduates under curriculum year 2002-2003. 
Correlation between Academic Performance in Medical Technology Professional Subjects and Licensure Examination Results

Table 4. Graduates' Performance in the Different Subtests of the Medical Technology Licensure Examination in Three Curriculum Years

\begin{tabular}{|c|c|c|c|}
\hline Subjects & CY 2002-2003 & CY 2005-2006 & CY 2006-2007 \\
\hline Clin. Chemistry & 70.81 & 75.17 & 76.53 \\
\hline Micro-Para & 75.53 & 76.85 & 82.35 \\
\hline Hematology & 69.79 & 72.04 & 78.47 \\
\hline BB-Serology & 72.86 & 76.19 & 76.53 \\
\hline Clin. Microscopy & 73.48 & 78.92 & 81.93 \\
\hline Histopath-MTLE & 73.20 & 76.59 & 80.44 \\
\hline MEAN & $\mathbf{7 2 . 6 1}$ & $\mathbf{7 5 . 9 6}$ & $\mathbf{7 9 . 3 8}$ \\
\hline Verbal Interpretation & Unsatisfactory & Barely Satisfactory & Fairly Satisfactory \\
\hline
\end{tabular}

\subsection{Correlation between Academic Performance in Medical Technology Professional Subjects and Results of Licensure Examination}

Academic performance in medical technology professional subjects and results of licensure examination are all shown to have a significant correlation. However, it only revealed to have "low" correlation to "substantial" correlation in majority of graduates who took the licensure examination from September 2006 to September 2010 and belonging to three curriculum years. The computed coefficient of correlation ranges from 0.279 to 0.526 . The result showed that academic performance, in a way affect the ratings in the different subtest of the licensure examination.

Table 5. Correlation between Academic Performance in Medical Technology Professional Subjects and Results of Licensure Examination

\begin{tabular}{|l|c|c|c|c|c|c|}
\hline \multicolumn{1}{|c|}{ Subjects } & \multicolumn{2}{c|}{ CY 2002-2003 } & \multicolumn{2}{c|}{ CY 2005-2006 } & \multicolumn{2}{c|}{ CY 2006-2007 } \\
\hline & R coefficient & P value & R coefficient & P value & R coefficient & P value \\
\hline Clin. Chemistry & 0.397 & $* 0.000$ & 0.504 & $* 0.000$ & 0.521 & $* 0.000$ \\
\hline Micro-Para & 0.340 & $* 0.000$ & 0.485 & $* 0.000$ & 0.465 & $* 0.000$ \\
\hline Hematology & 0.367 & $* 0.000$ & 0.512 & $* 0.000$ & 0.367 & $* 0.000$ \\
\hline BB-Serology & 0.480 & $* 0.000$ & 0.526 & $* 0.000$ & 0.279 & $* 0.000$ \\
\hline Clin.Microscopy & 0.156 & $* 0.000$ & 0.516 & $* 0.000$ & 0.502 & $* 0.000$ \\
\hline $\begin{array}{l}\text { Histopath- } \\
\text { MTLE }\end{array}$ & 0.329 & $* 0.000$ & 0.394 & $* 0.000$ & 0.347 & $* 0.000$ \\
\hline
\end{tabular}

*p value is significant at 0.01 level

\subsection{Predictors of the Medical Technology Licensure Examination Performance}

Table 6. Predictors of Medical Technology Licensure Examination Performance (September 2006 - March 2009)

\begin{tabular}{|l|c|c|}
\hline \multicolumn{1}{|c|}{ Predictors } & Regression coefficient & R Square \\
\hline Curriculum Year 2002-2003 & & \\
Blood Banking-Serology & 0.504 & 0.254 \\
Microbiology-Parasitology & 0.516 & 0.266 \\
\hline Clinical Chemistry & 0.525 & 0.276 \\
\hline Curriculum Year 2005-2006 & & 0.367 \\
\hline Blood Banking-Serology & 0.606 & \\
Curriculum Year 2006-2007 & & 0.293 \\
\hline Clinical Chemistry & 0.557 & \\
\hline
\end{tabular}

Data in revealed that for graduates under curriculum year 2002-2003 and who took the medical technology licensure examinations conducted from September 2006 to March 2009, three (3) medical technology professional subjects were identified as predictors. It also shows that only the combined subjects of Blood Banking - Serology was identified as predictor of medical technology licensure examination performance for graduates classified under curriculum 2005-2006 and took the licensure examination from September 2009 to March 2010. Lastly, the predictor of licensure examination performance for graduates belonging to curriculum year 2006-2007 and took the examination on September 2010 is Clinical Chemistry subject. 


\section{DISCUSSION}

This study aimed to determine the academic performance of the graduates in the medical technology professional subjects and subtests in licensure examination and to correlate the academic performance and performance in subtests of the licensure examination.

The academic performance of the graduates in three different curriculum years were found to be "satisfactory". However, graduates belonging to curriculum year 2005-2006 performed higher than those graduates under curriculum year 2002-2003 and curriculum year 2006-2007. Further perusal of the data also reveals that this group of graduates under curriculum year 2005-2006 excelled in all of the medical technology professional subjects' despite of the fact that they took four (4) professional subjects (Clinical Chemistry 1, Microbiology, Parasitology and Clinical Microscopy) during the 1st semester of third year. As regard academic performance in various medical technology professional subjects of graduates under curriculum 2006-2007 and curriculum year 2002-2003, minimal differences maybe noticed which suggest that even if some subjects like Microbiology and Hematology were divided into subparts and offered in separate semesters, it did not significantly contribute in improving graduates' academic performance. However, such observation maybe verified by using larger number of graduates under curriculum 2006-2007.

In the performance of graduates in the different subtests of the medical technology licensure examination in three curriculum years. Graduates under curriculum 2006-2007 performed better in all of the subtests of the licensure examination as compared to graduates belonging to curriculum year 2002-2003 and 2006- 2007. In addition, performance in the licensure examination also improved during curriculum year 2005-2006 as evidenced by a passing average rate of 75.96, much higher than those obtained by graduates under curriculum year 2002-2003. The gradual improvement in the performance of graduates maybe attributed from the policy of the College to rigidly screen graduates before allowing them to take the licensure examination. Pre-board examination or Revalida is usually administer to determine who among the graduates will academically qualify to take the licensure examination. Those who fail will not be given the clearance to take the said examination. This policy was first implemented among September 2009 batch of examinees

Blood Banking and Serology were found to have the highest correlation coefficient of all the subjects in two curriculum years (2002-2003 and 2005-2006). The findings of this study validates the results of the study of Mabolo [1] who also identified Blood Banking and Serology as the medical technology professional subject which showed the highest coefficient correlation with similar subtest in the licensure examination. However, these findings should not be misconstrued as a positive feedback since graduates' performance in the licensure examination for this subject varies from "unsatisfactory" to "barely satisfactory" from Sept 2006 to March 2009. This proved that what were emphasized in the classroom for these subjects did not sufficiently equipped students with essential knowledge during their licensure examination.

There is a high correlation coefficient noted in the graduates belonging to curriculum years 20052006. This implied that most of the content of board related subjects as prescribed in curriculum year 2005-2006 are aligned on those questions given in the different subtests of the licensure examination. These findings are almost close to that of Harris [2] which pointed out a moderate correlation between academic performance and result of licensure examination among nursing graduate. On the other hand, Clinical Chemistry and Micro-Para have the highest correlation coefficient in curriculum years 2006-2007. The positive outcome may be ascribed from the curriculum revision during curriculum year 2006-2007 in which Microbiology subject were subdivided into Microbiology 1 and 2 and offered in different semesters. Another is on Clinical Chemistry which is divided into three (3) instead of the originally two (2) semester subjects [3]. According to Timperley et al. [4], in order for effective learning to occur, the content must be in the right sequence since all areas of learning sit in the appropriate place in terms of scoping and sequencing learning

Blood Banking and Serology, Clinical Chemistry and Microbiology and Parasitology were found to be predictor of success in the licensure examination. The present findings are similar with that of Mabolo [1], which states that Blood Banking and Serology subjects being part of Seminar classes was recognized as predictor of performance in medical technology licensure examination. However,the result of Racqueno [5] differs, in which Clinical Microscopy subject was identified as the best predictor of board examination performance from 1994 to 1996. 


\section{CONCLUSION}

Based on the findings of the study it is concluded that the general, majority of the graduates showed average academic performance in most medical technology professional subjects and performed low in the different subtests of the medical technology licensure examination. Also, there is a low to substantial correlation between academic performance and results of the licensure examination. Furthermore, Blood Banking and Chemistry subjects predict performances in the medical technology licensure examination. There is a need to proposed an in-house review enhancement program to improve performance of graduates in the medical technology licensure examination and to assist faculty members and reviewers in identifying concepts to be emphasized among prospective candidates who will take the licensure examination in the future.

\section{REFERENCES}

[1] Mabolo, E. (1995). The Predictive Validity of the Performance in Seminar Classes to the Medical Technology Board Examination Results. Unpublished Master's thesis, Centro Escolar University, Manila.

[2] Harris, Martina S. (2006). Investigation of Prerequisite Science Course Performance and Cumulative Grade Point Average as Predictors of Success on National Council Licensure Exam for Registered Nurses. ETD Collection for Tennessee State University. Paper AAI3211924.

[3] CHED Memorandum Order No. 14 (2006). Policies Standards and Guidelines for Medical Technology Education

[4] Timperley, H., Wilson, A., Barrar H., Fung, I. (2007) Teacher Professional Learning and Development: Best Evidence Synthesis Iteration Wellington, New Zealand: Ministry of Education

[5] Racqueno, A. (1996). Predictive Validity of the Academic Achievement in Professional Subjects of Medical Technology Students in Relation to their Board Examination Performance. Unpublished Master's thesis, Centro Escolar University, Manila.

\section{AUTHOR'S BIOGRAPHY}

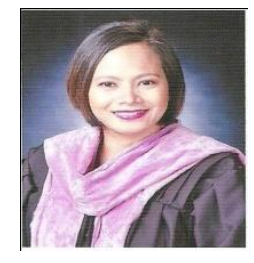

Dr. Irynne Dario Cabanban, is an Associate Professor 6 at Centro Escolar University Manila, teaching professional subjects in the School of Nursing and Medical Technology. She is a registered Nurse and Medical Technologist, a former researcher at a national research institute and a trainer of health professionals specializing in TB Microscopy. Since she opted to pursue a teaching career, she obtained her Masters of Arts in Teaching and Doctor of Philosophy Major in Curriculum and Supervision in her affiliated institution. She is a member of the Philippine Nursing Research Society, Philippine Nurses Association and the Philippine Association of Medical Technologists. Dr. Cabanban continuously expands her knowledge by doing researches both in the field of Education and Public Health and participated in various national and international research forums.

Citation: Irynne D. Cabanban, "Correlation between Academic Performance in Medical Technology Professional Subjects and Licensure Examination Results" International Journal of Humanities Social Sciences and Education (IJHSSE) vol 4, no. 9, 2017, pp. 46-51. doi:dx. doi.org/10.20431/2349-0381.0409007.

Copyright: () 2017 Authors. This is an open-access article distributed under the terms of the Creative Commons Attribution License, which permits unrestricted use, distribution, and reproduction in any medium, provided the original author and source are credited. 